\title{
Analysis of $\beta^{\prime}\left(\mathrm{Cu}_{4} \mathrm{Ti}\right)$ Precipitation During Isothermal Aging of a $\mathrm{Cu}-4 \mathrm{wt} . \% \mathrm{Ti}$ Alloy
}

\author{
Victor Manuel Lopez-Hirata* ${ }^{a}$, Felipe Hernandez-Santiago ${ }^{a}$,Maribel Leticia Saucedo-Muñoz ${ }^{a}$,
}

\author{
Hector Javier Dorantes-Rosales ${ }^{a}$, Ana Maria Paniagua-Mercado ${ }^{a}$
}

\author{
${ }^{a}$ Escuela Superior de Ingeniería Química e Industrias Extractivas (ESIQIE), Instituto Politecnico \\ Nacional, Edif. 7 Col. Lindavista GAM, Ciudad de México, Mexico
}

Received: February 17, 2018; Revised: May 10, 2018; Accepted: July 04, 2018

\begin{abstract}
This work analyzed experimental and numerically the growth kinetics of $\beta$ ' precipitation of a Cu$4 \mathrm{wt} . \% \mathrm{Ti}$ alloy after aging at 400,500 and $600{ }^{\circ} \mathrm{C}$ for times from $0.0166 \mathrm{~h}$ to $200 \mathrm{~h}$. Results indicated that the precipitation process is almost controlled by nucleation and growth during aging at $400{ }^{\circ} \mathrm{C}$, originating a slow growth kinetics of precipitation. In contrast, the coarsening of precipitates dominates the precipitation process during aging at 500 and $600{ }^{\circ} \mathrm{C}$. The interfacial energy of interface between the a matrix phase and $\beta^{\prime}$ precipitates was determined to be about $0.1135,0.0980$ and $0.0725 \mathrm{Jm}^{-2}$ for aging at 400,500 and $600{ }^{\circ} \mathrm{C}$, respectively. These values suggest a coherent interface which is in agreement with the flat faces of $\beta^{\prime}$ cuboid precipitates. Calculated Time-Temperature-Precipitation diagram for the $\beta^{\prime}$ precipitation indicated good agreement with experimental results. Precipitation hardening was higher for the slower growth kinetics of precipitation.
\end{abstract}

Keywords: $\mathrm{Cu}$-Ti alloys, precipitation, growth kinetics, numerical simulation.

\section{Introduction}

$\mathrm{Cu}$-Ti alloys are prone to have precipitation hardening after isothermal aging for alloy compositions of about 1-5wt.\% $\mathrm{Ti}^{1-4}$. Age-hardenable $\mathrm{Cu}-\mathrm{Ti}$ alloys have high tensile strength and good formability and they are used as connector materials in electronic and electrical components ${ }^{5,6}$; nevertheless, its conductivity is less than the half of that corresponding to $\mathrm{Cu}-\mathrm{Be}$ alloys. Therefore, the application of $\mathrm{Cu}$-Ti alloys has been focused on mechanical properties. In order to obtain good mechanical properties, $\mathrm{Cu}$-Ti alloys are solution treated above $800{ }^{\circ} \mathrm{C}$ and then quenched and the aging process is carried out at temperatures of 400-500 ${ }^{\circ} \mathrm{C}$. As a result of aging, the fcc $\mathrm{Cu}$-rich supersaturated solid solution decomposes spinodally to form a disordered fcc Ti-rich phase and then become order to form the metastable tetragonal $\beta^{\prime} \mathrm{Cu}_{4}$ Ti phase which is responsible for the good mechanical properties of these alloys ${ }^{1,7,8}$. After prolonged aging, the cellular precipitation of the stable orthorhombic $\beta \mathrm{Cu}_{4}$ Ti phase takes place by nucleation and growth on grain boundaries which is the main cause for the decrease in the mechanical strength in the later stage of aging ${ }^{1}$. The mechanical strength of $\mathrm{Cu}$-Ti alloys has been improved either by the addition of a third alloying element such as Chromium, zirconium, carbon, nitrogen or hydrogen ${ }^{9-11}$ or by using cold work previously to the aging treatment ${ }^{12,13}$. In the former case, the precipitation sequence was similar to that observed in the binary alloy; however, the presence of a different precipitates such as titanium chromide, nitride, carbide or hydride was also reported to occur during aging ${ }^{9-11}$. In the latter case, the cold work, used after solution treatment and quenching, has

"e-mail: vlopezhi@prodigy.net.mx. been reported ${ }^{12,14}$ to promote the precipitation of titanium on dislocations and to inhibit the precipitation of the $\beta^{\prime} \mathrm{Cu}_{4} \mathrm{Ti}$ and $\beta \mathrm{Cu}_{4}$ Ti phases during aging.

Recently, TC-PRISMA software has been used to analyze the precipitation process of different aged alloys ${ }^{15}$. This software is based on the solution of the Langer-Schwartz (LS) and modified LS (MLS) theories and the Kampmann and Wagner numerical model ( $\mathrm{N}$ model $)^{16}$, and it has been used to analyze the precipitation kinetics of different phases during aging in steels and nonferrous alloys ${ }^{16-18}$. This software permits, for example, to determine the size, distribution size, density number and composition of precipitated phases, as well as the Time-Temperature-Precipitation (TTP) diagram in multiparticles, multiphases and multicomponents alloy systems. Besides, the nucleation site can be selected among grain boundaries, bulk and dislocations. Thus, the use of Thermo-Calc PRISMA would be a good alternative to complement the precipitation analysis of $\beta$ 'phase in the aged $\mathrm{Cu}$-Ti alloys.

Thus, the purpose of this work is to study experimental and numerically the growth kinetics of $\beta$ ' phase precipitation in an isothermally aged $\mathrm{Cu}-4 \mathrm{wt}$. \% Ti alloy in order to obtain the Time-Temperature-Precipitation (TTP) diagrams, as well as the determination of the interfacial energy between the $\alpha$ matrix and $\beta$ 'precipitates.

\section{Experimental Method}

A Cu-4wt.\% Ti alloy was melted with an electric furnace using $99.99 \%$ purity titanium and $99.999 \%$ purity copper in an alumina crucible under an argon gas atmosphere. The alloy ingot was homogenized at $950{ }^{\circ} \mathrm{C}$ for one week 
and subsequently cold rolled to obtain plate specimens of about $30 \times 10 \times 5 \mathrm{~mm}$. These specimens were encapsulated in air-evacuated and Ar gas filled quartz tube and then solution treated at $900{ }^{\circ} \mathrm{C}$ for $1 \mathrm{~h}$ in an electrical resistance furnace, and subsequently quenched in ice-water in order to obtain solution treated specimens. These specimen were aged at temperatures of 400,500 and $600{ }^{\circ} \mathrm{C}$ for times up to $200 \mathrm{~h}$. The Transmission Electron Microscope (TEM) disc specimens of approximately $3 \mathrm{~mm}$ were thinned using the twin-jet electropolishing technique in a solution of 75 vol. $\%$ methanol and 25 vol. $\%$ nitric acid at $-60{ }^{\circ} \mathrm{C}$. TEM specimens were mounted on a Be-specimen holder and observed with a TEM JEM-2000FX-II at $200 \mathrm{kV}$, equipped with a Noran EDXS. Vickers hardness test was determined in all the heat treated specimens using 10 determinations with $500 \mathrm{~g}$ and $12 \mathrm{~s}$.

\section{Numerical Method}

Thermo-Calc software was used to analyze the stability of phases and the coarsening constant and interfacial energy $\gamma$ between matrix and precipitates. Likewise, the analysis of precipitation was pursued in the aged $\mathrm{Cu}-4$ wt. \% Ti alloy employing the Thermo-Calc (TC) PRISMA software. The kinetic and thermodynamic data was determined from the Thermo-Calc databases for CUDEMO and MCUDEMO ${ }^{15}$. A homogeneous nucleation was assumed for the precipitation simulation in the austenite matrix, named bulk nucleation in TC-PRISMA. The precipitate shape was considered to be cuboid considering a cube elastic-strain energy for the $\alpha$ phase matrix and precipitate with the following elastic constants: $\mathrm{c}_{11}=168.4 \mathrm{GPa}, \mathrm{C}_{12}=121.4 \mathrm{GPa}$ and $\mathrm{c}_{44}=75.4 \mathrm{GPa}$.

\section{Results and Discussion}

\section{a) Temporal Evolution of Precipitation}

The temporal evolution of precipitation of $\beta^{\prime}$ phase in the $\mathrm{Cu}$-rich $\alpha$ phase matrix is illustrated in the Bright-Field (BF) Transmission Electron Micrographs corresponding to the $\mathrm{Cu}-4$ wt.\% Ti alloy aged at 400,500 and ${ }^{\circ} \mathrm{C}$ for different times, as shown in Figs. 1-3, respectively. The $\beta^{\prime}$ precipitates has a cuboid morphology and they are aligned on the $<100>$ direction of the $\alpha$ phase matrix for all aging temperatures because of its low value of elastic-strain energy ${ }^{7,19}$. As aging progresses, the morphology changes to plates also aligned with respect to the matrix phase, Figs. 1(d), 2(d) and 3 (c). The electron diffraction pattern, shown in Fig. 1 (c), indicates clearly the presence of supereflections spots between those corresponding to the matrix phase which confirms that the $\beta$ 'phase has a $\mathrm{Cu}_{4}$ Ti crystalline structure. Table 1 shows the average equivalent radius and its corresponding dispersion error determined for the $\beta$ 'precipitates after aging at 400 , 500 and $600{ }^{\circ} \mathrm{C}$ for different times. An increase in precipitate

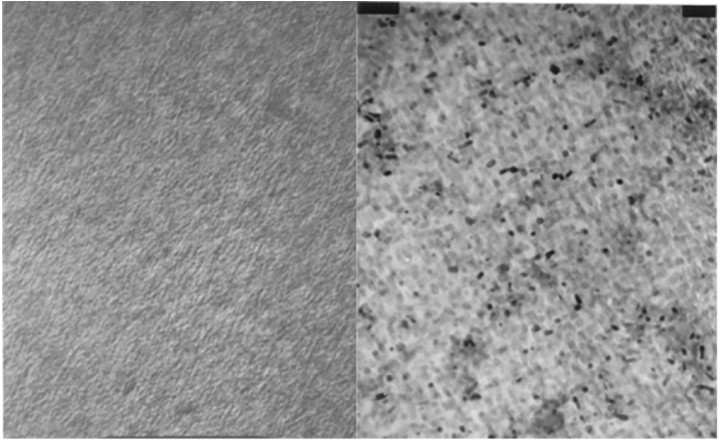

(a)

(b)

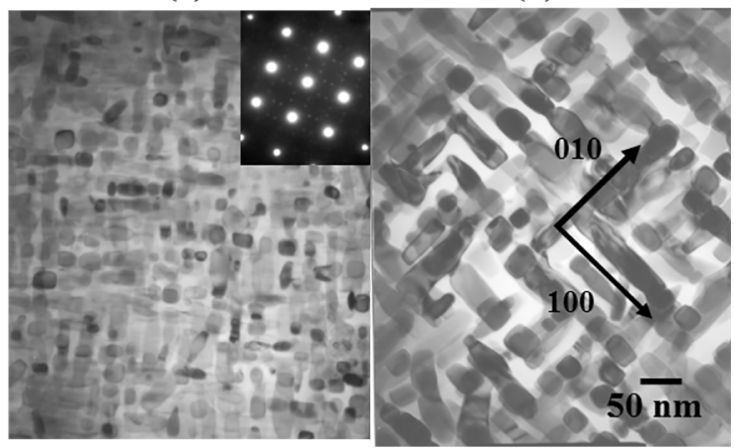

(c)

(d)

Figure 1. BF-TEM micrographs of $\mathrm{Cu}-4 \mathrm{wt}$. \% Ti alloy aged at $400{ }^{\circ} \mathrm{C}$ for (a) $5 \mathrm{~h}$, (b) $25 \mathrm{~h}$, includes its corresponding electron diffraction pattern, (c) $100 \mathrm{~h}$ and (d) $200 \mathrm{~h}$. (a)

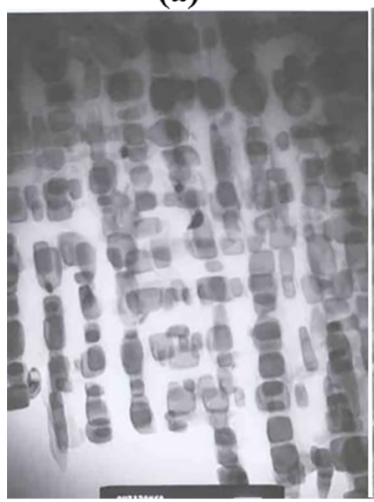

(c)

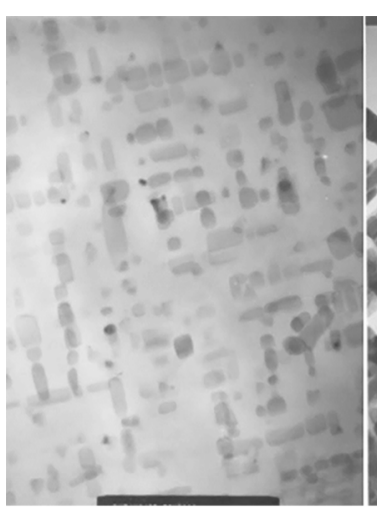

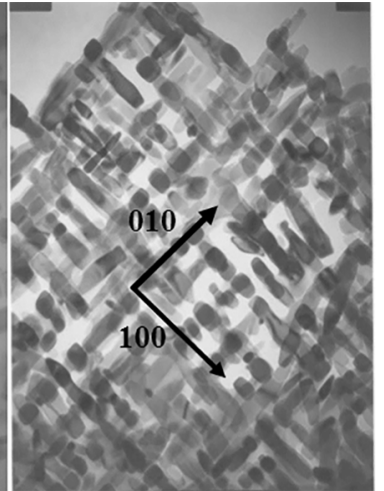

(b)

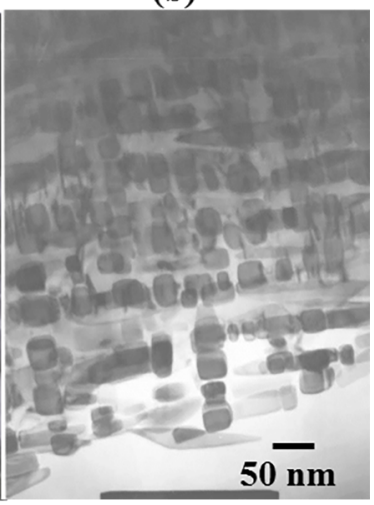

(d)

Figure 2. BF-TEM micrographs of $\mathrm{Cu}-4 \mathrm{wt}$.\% $\%$ Ti alloy aged at 500 ${ }^{\circ} \mathrm{C}$ for (a) $0.0166 \mathrm{~h}$, (b) $0.5 \mathrm{~h}$, (c) 1 and (d) $5 \mathrm{~h}$. 
Table 1. Variation of precipitate equivalent radius with time for aging at 400,500 and $600{ }^{\circ} \mathrm{C}$

\begin{tabular}{lccc}
\hline \multirow{2}{*}{ Time $(\mathrm{h})$} & \multicolumn{3}{c}{ Radius $(\mathrm{nm})$} \\
\hline 0.166 & $400{ }^{\circ} \mathrm{C}$ & $500{ }^{\circ} \mathrm{C}$ & $600{ }^{\circ} \mathrm{C}$ \\
0.5 & --- & $13.3 \pm 5.0$ & $14.1 \pm 4.0$ \\
1 & --- & $21.4 \pm 6.0$ & $18.8 \pm 7.1$ \\
5 & $9.2 \pm 2.5$ & $22.06 \pm 8.2$ & $26.6 \pm 9.0$ \\
25 & $16.3 \pm 2.9$ & $26.8 \pm 10.1$ & --- \\
100 & $18.6 \pm 3.2$ & --- & --- \\
200 & $19.8 \pm 5.1$ & --- & --- \\
\hline
\end{tabular}

radius can be noted with aging time and temperature. The discontinuous or cellular precipitation of the $\beta$ 'phase can be noted clearly for the alloy specimen aged at $600{ }^{\circ} \mathrm{C}$, Fig. 3 (d). This type of precipitation was also observed to be present after aging at 400,500 and $600{ }^{\circ} \mathrm{C}$ for $100,0.5$ and $0.166 \mathrm{~h}$, respectively

\section{b) Thermo-Calc analysis of precipitation}

The Thermo-Calc calculated amount of all phases versus temperature is shown in Fig. 4. This plot indicates clearly that the $\alpha$ and $\beta^{\prime}$ phases are present at temperatures between 500 and $840{ }^{\circ} \mathrm{C}$. This figure also suggests that the precipitation reaction:

$$
\alpha_{s s s} \rightarrow \alpha+\beta^{\prime}
$$

It may occur after aging at those temperatures. The volume fraction of $\beta$ ' precipitates increases with the decrease in temperature.

Table 2 shows the Thermo-Calc calculated values of interfacial energy for the interface of $\alpha$ matrix and $\beta^{\prime}$ precipitate. This value decreases with the increase in temperatures, as expected in the case of free energy due to the increase in entropy ${ }^{16}$. The magnitude order, $0.03 \mathrm{Jm}^{-2}$, suggests a coherent interface ${ }^{20}$. This table also indicates the values of coarsening constant $\mathrm{k}$ for 400,500 and $600{ }^{\circ} \mathrm{C}$. Unsurprisingly, this parameter increases with temperature because of the increase in atomic diffusion ${ }^{16}$.

\section{c) Thermo-Calc PRISMA analysis of precipitation}

The experimental and calculated variation of equivalent radius for $\beta^{\prime}$ precipitates with time are shown in Figs. 5 (a-c) for the $\mathrm{Cu}-4$ wt. \% Ti alloy aged at 400, 500 and $600{ }^{\circ} \mathrm{C}$. The continuous line and triangle points correspond to the calculated and experimental values, respectively. The error bar of radius measurements is also shown in Figs. 5 (a-c) which indicates, in general, a good agreement between calculated and experimental values. This plot of shows clearly three characteristic stages: a continuous and slow increase in precipitate radius for short aging times, Fig. 5(a), because of the rise of nucleation rate with time. The number density

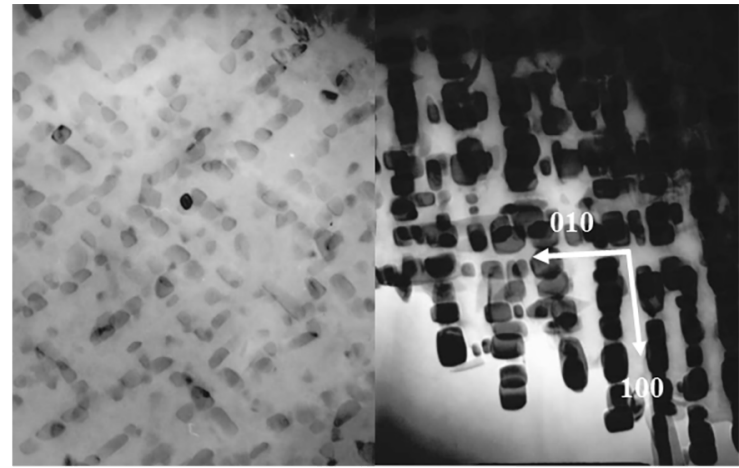

(a)

(b)

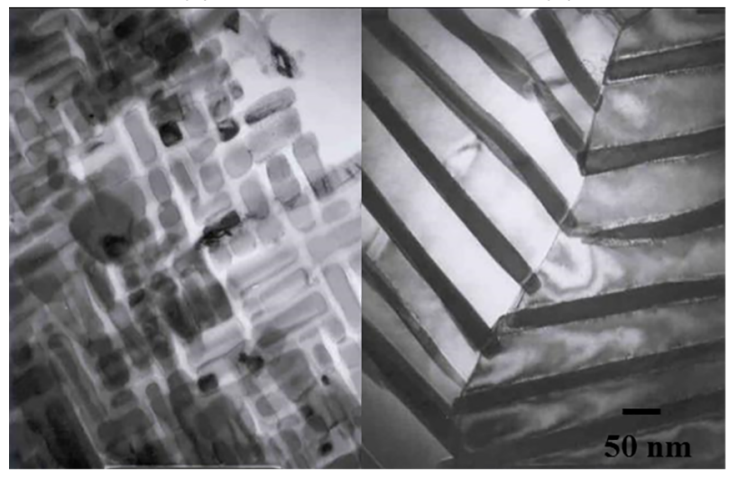

(c)

(d)

Figure 3. BF-TEM micrographs of Cu-4wt.\%Ti alloy aged at 600 ${ }^{\circ} \mathrm{C}$ for (a) $0.0166 \mathrm{~h}$, (b) $0.166 \mathrm{~h}$, (c) $1 \mathrm{~h}$ and (d) $5 \mathrm{~h}$.

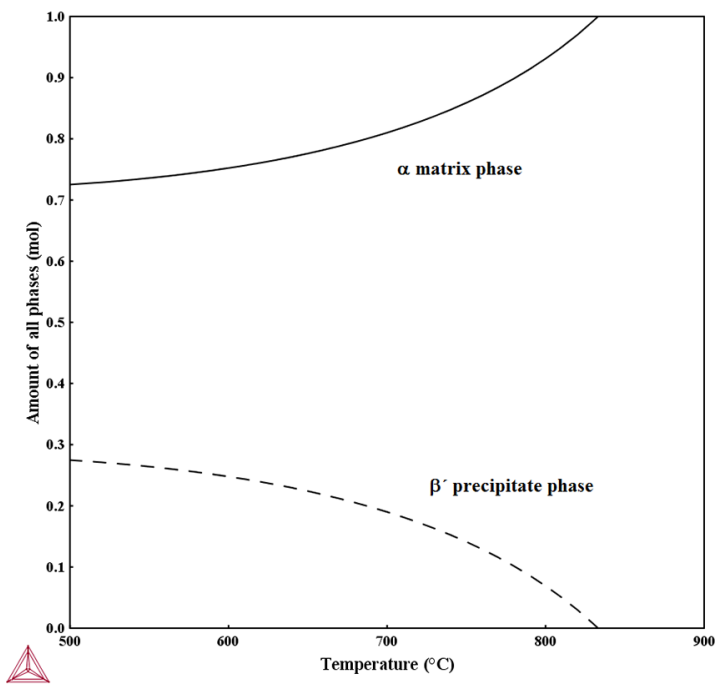

Figure 4. Thermo-Calc calculated plot of amount of all phases versus temperature.

of precipitates also increases with aging time, as shown in Fig. 6(a). Then, the radius increases more rapidly after $1 \mathrm{~h}$ of aging time, following a parabolic law of $t^{1 / 2}$ which can be attributable to the growth stage. The nucleation rate subsequently becomes zero because either the solute 
Table 2. Thermo-Calc calculated interfacial energy between precipitate and matrix and coarsening constant, and experimental interfacial energy for aging temperatures

\begin{tabular}{lccc}
\hline & \multicolumn{2}{c}{ Thermo-Calc } & Experimental \\
\hline $\mathrm{T}\left({ }^{\circ} \mathrm{C}\right)$ & $\gamma\left(\mathrm{Jm}^{-2}\right)$ & $\mathrm{k}\left(\mathrm{m}^{3} \mathrm{~s}^{-1}\right)$ & $\gamma\left(\mathrm{Jm}^{-2}\right)$ \\
400 & 0.0339 & $1.1041 \mathrm{x}$ & 0.1135 \\
& & $10-31$ & \\
& & $2.2334 \mathrm{x}$ & 0.0980 \\
500 & 0.0325 & $10-29$ & \\
& & $1.2776 \mathrm{x}$ & 0.0725 \\
600 & 0.0309 & $10-27$ & \\
\hline
\end{tabular}

supersaturation turns into zero or all nucleation sites are used $^{16,21}$. As a result of this, the number density and the precipitate radius remain constant, as shown in Fig. 6(a-c) and 5 (a), respectively. As aging progresses, the number density starts decreasing with time, following a $t^{1}$ power law, and the growth kinetics of precipitate radius with time follows a slope of $1 / 3, t^{1 / 3}$. That is, the growth kinetics corresponds to the coarsening stage of precipitates and it follows the Lifshitz-Slyozov-Wagner theory for diffusioncontrolled theory ${ }^{16}$. According to the previously mentioned explanation, most of the experimental points for the growth kinetics of precipitates at $400^{\circ} \mathrm{C}$ are located in the nucleation and growth stage, while the experimental points at 500 and $600{ }^{\circ} \mathrm{C}$ corresponds to the coarsening stage. It is important to mention that the interfacial free energy $\gamma$ was changed in order to find the best fit of experimental values with the calculated curves. They are shown in Table 2 and decrease as aging temperature increases. These values are higher than the Thermo-Calc determined ones. The low values calculated by Thermo-Calc can be attributed to the fact that the calculation of interfacial energy uses thermodynamic data and assumes a complete coherent interface; however, the interfacial energy is also dependent on several factors such as crystallographic misorientation, elastic misfit strains, degree of coherency, and solute segregation ${ }^{21}$, which may cause higher energy values. These values between 0.07 and $0.11 \mathrm{Jm}^{-2}$ show are in good agreement with the values of $0.1-0.2 \mathrm{Jm}^{-2}$ reported for coherent $\beta^{\prime}$ precipitates in the literature ${ }^{7,17,22}$, and it suggests that the interface between matrix and precipitates should be coherent ${ }^{20}$, which is in agreement with the cuboid morphology of $\beta^{\prime}$ precipitates, as shown in Figs. 1-3.

The TC-PRISMA calculated Time-Temperature-Precipitation TTP diagram of the $\mathrm{Cu}-4$ wt. \% Ti alloy is shown in Fig. 7. This was calculated using an average value of $0.0946 \mathrm{Jm}^{-2}$ determined from the experimental ones shown in Table 2. This figure shows that the fastest precipitation kinetics corresponds to an aging at about $500{ }^{\circ} \mathrm{C}$ for $0.01 \mathrm{~h}$. This figure also includes the TEM micrographs for the alloy specimens aged at $400^{\circ} \mathrm{C}$ for $5 \mathrm{~h}$, and 500 and $600{ }^{\circ} \mathrm{C}$ for 0.166 and $1 \mathrm{~h}$. These TEM images suggests that the start of $\beta^{\prime}$ precipitation is very similar for aging at 500 and $600{ }^{\circ} \mathrm{C}$ which is in good

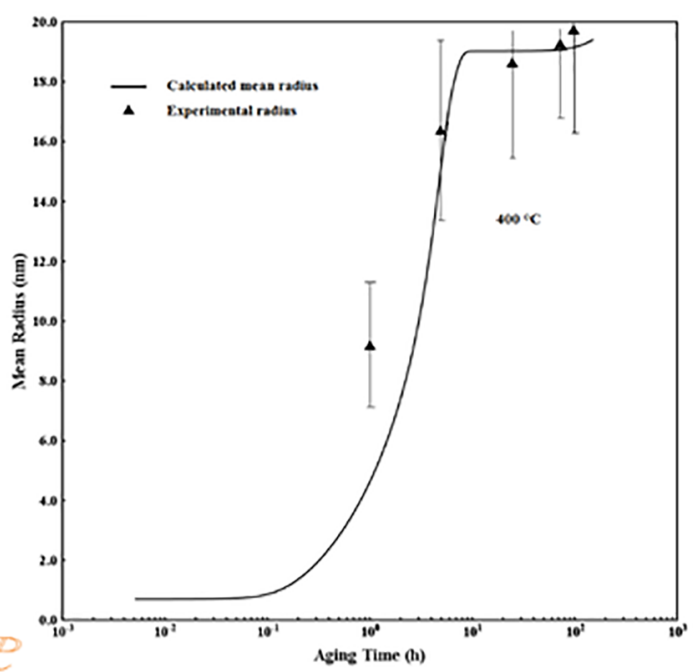

(a)

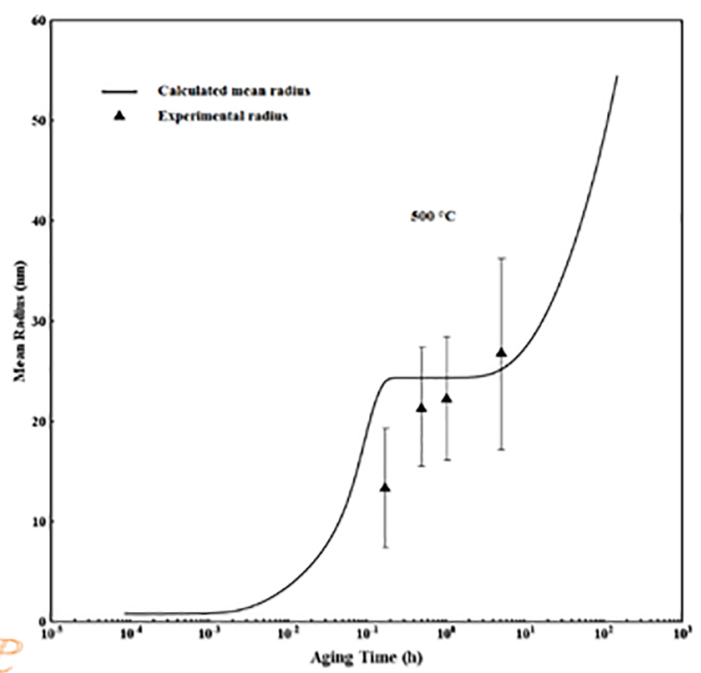

(b)

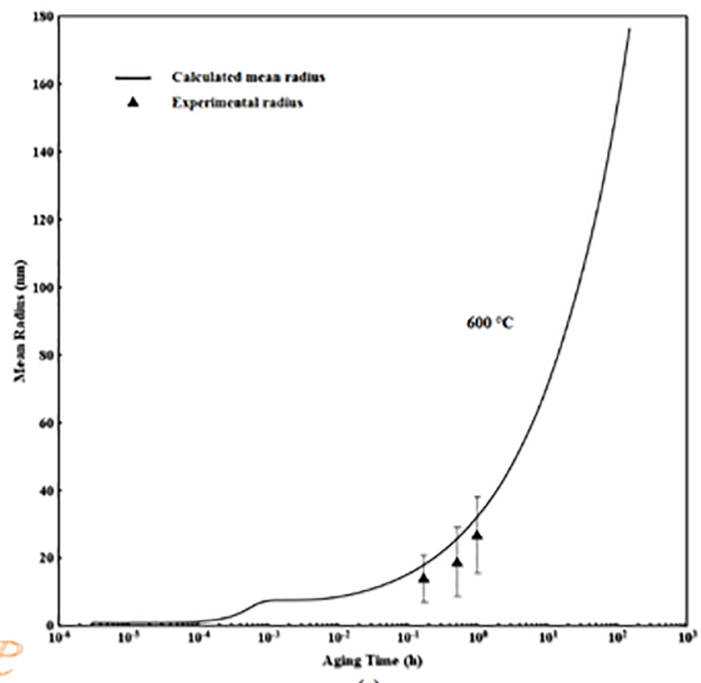

(c)

Figure 5. TC-PRISMA calculated plot of mean radius of $\beta^{\prime}$ precipitate versus time for $\mathrm{Cu}-4 \mathrm{wt} . \% \mathrm{Ti}$ alloy aged at (a) $400{ }^{\circ} \mathrm{C}$, (b) $500{ }^{\circ} \mathrm{C}$ and (c) $600{ }^{\circ} \mathrm{C}$. 


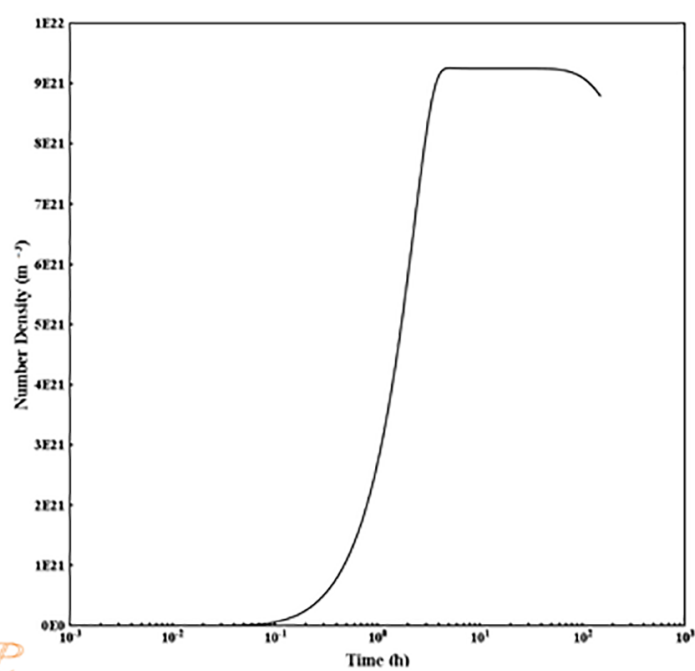

(a)

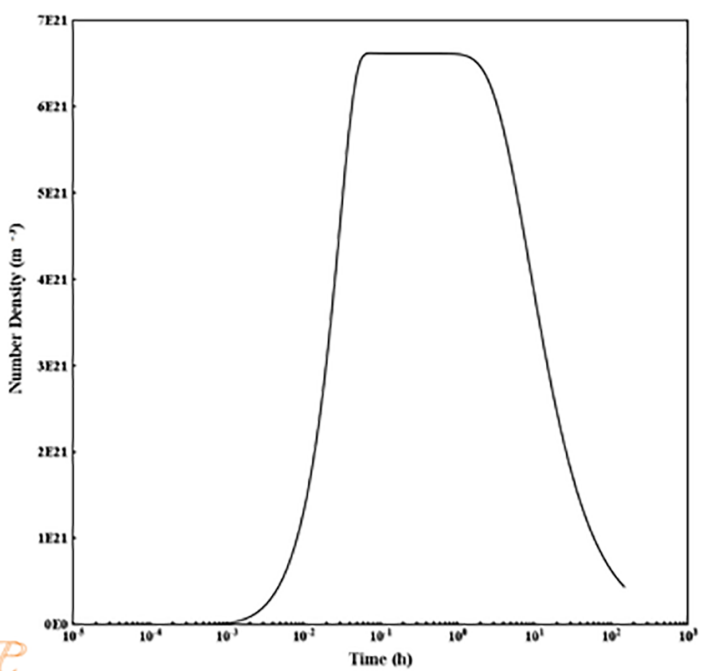

(b)

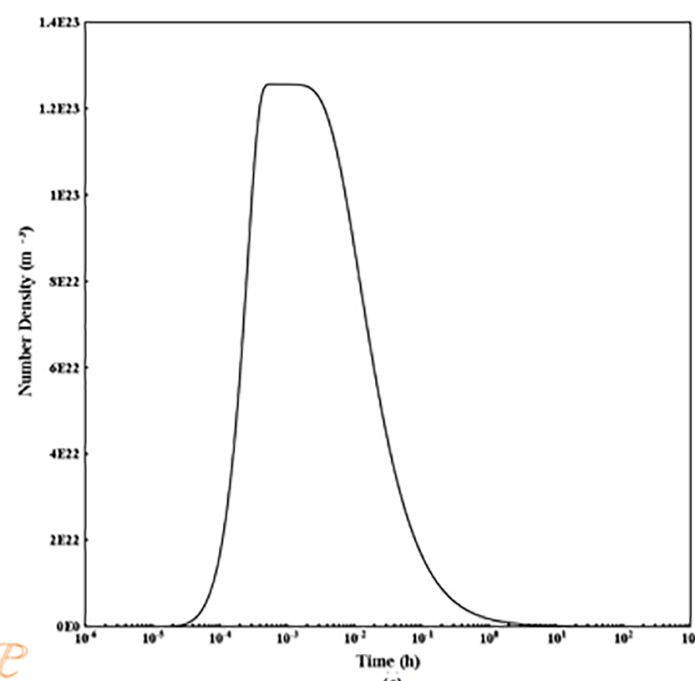

Figure 6. TC-PRISMA calculated plot of number density of $\beta^{\prime}$ precipitate versus time for $\mathrm{Cu}-4 \mathrm{wt} . \% \mathrm{Ti}$ alloy aged at (a) $400{ }^{\circ} \mathrm{C}$, (b) $500{ }^{\circ} \mathrm{C}$ and (c) $600{ }^{\circ} \mathrm{C}$.

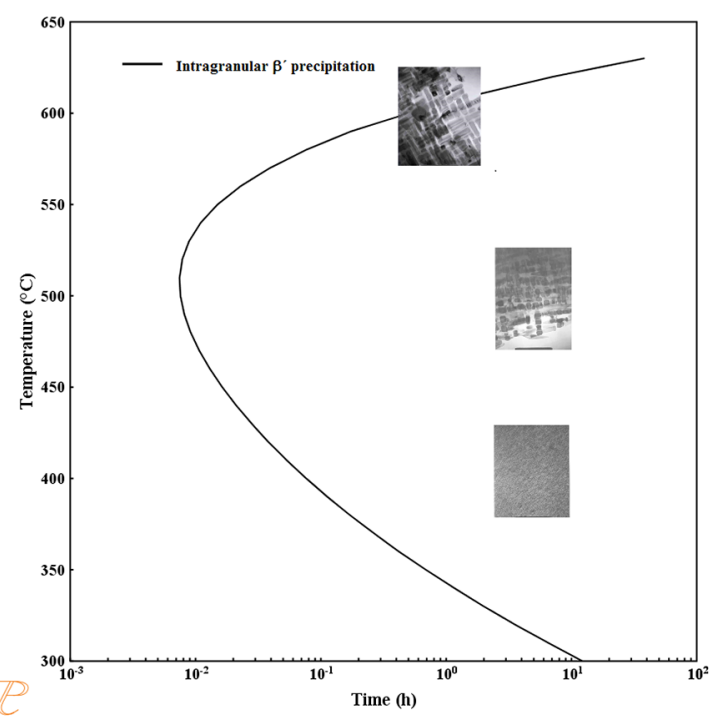

Figure 7. TC-PRISMA calculated TTP diagram.

agreement with the growth kinetics of precipitation shown in the calculated TTP diagram. Nevertheless, the growth kinetics of precipitation at $400{ }^{\circ} \mathrm{C}$ is much faster than that detected experimentally, Fig. 1 . This can be attributable to the constant value of interfacial energy, $0.0946 \mathrm{Jm}^{-2}$, used for the present calculation. That is, the energy value should be higher at $400{ }^{\circ} \mathrm{C}$ which might cause a higher activation energy for nucleation and consequently the nucleation rate would be expected to be slower ${ }^{20}$ than that of the TTP diagram.

\section{d) Aging curves}

Figure 8 shows the aging curves, plot of hardness as a function of aging time, for the $\mathrm{Cu}-4 \mathrm{wt}$. \% Ti alloy aged at 400,500 and $600{ }^{\circ} \mathrm{C}$. The aging curves corresponding to 500 and $600{ }^{\circ} \mathrm{C}$ show an increase in hardness, then the hardness peak is reached and finally this decreases as a result of the discontinuous precipitation and coarsening process

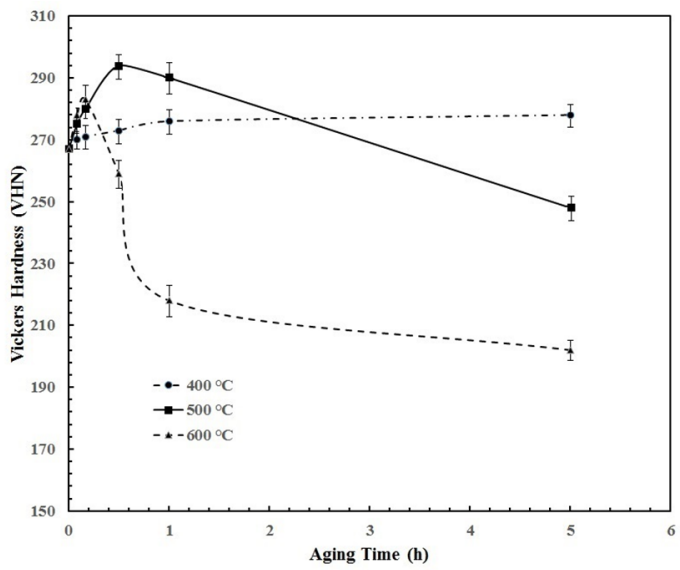

Figure 8. Aging curves of $\mathrm{Cu}-4 \mathrm{wt}$. \% Ti alloy aged at 400, 500 and $600{ }^{\circ} \mathrm{C}$ 
of precipitates. In contrast, aging at $400{ }^{\circ} \mathrm{C}$ presents a slow increase in hardness and the hardness peak, $370 \mathrm{VHN}$, is obtained after aging for $200 \mathrm{~h}$, not shown in Fig. 8. The highest and lowest hardness peaks correspond to the alloy specimens aged at $400{ }^{\circ} \mathrm{C}$ and $600{ }^{\circ} \mathrm{C}$. The hardness peaks of aging at 500 and $600{ }^{\circ} \mathrm{C}$ were reached more rapidly than that at $400{ }^{\circ} \mathrm{C}$ which agrees very well with the faster growth kinetics of precipitation, as shown in the calculated TTP diagram.

\section{Conclusions}

The numerical and experimental analysis of $\beta^{\prime}$ precipitation during aging at 400,500 and $600{ }^{\circ} \mathrm{C}$ permitted to state the following conclusions:

1. The numerical analysis of precipitation indicated that the nucleation and growth stage is dominant during aging at $400{ }^{\circ} \mathrm{C}$, while the precipitation during aging at 500 and $600{ }^{\circ} \mathrm{C}$ is mainly controlled by the coarsening stage.

2. The interfacial energy between matrix and precipitates was determined to be about $0.1135,0.0980$ and $0.0725 \mathrm{Jm}^{-2}$ for aging at 400,500 and $600{ }^{\circ} \mathrm{C}$, respectively, which is agreement with the coherent interface of cuboid $\beta^{\prime}$ precipitates.

3. Calculated TTP diagram showed a good concordance with the experimental results. The slowest growth kinetics at $400{ }^{\circ} \mathrm{C}$ promoted the highest precipitation hardening, while the fastest kinetics causes the lowest hardness.

\section{Acknowledgements}

The authors wish to acknowledge the financial support from Conacyt and SIP-IPN.

\section{References}

1. Soffa WA, Laughlin DE. High-strength age hardening coppertitanium alloys: redivivus. Progress in Materials Science. 2004;49(3-4):347-366.

2. Semboshi E, Inamoto E, Iwase A. Age-hardening behavior of a single-crystal Cu-Ti alloy. Materials Letters. 2014;131:90-93.

3. Nagarjuna S, Srinivas M, Balasugramanian K, Sarma DS. On the variation of mechanical properties with solute content in $\mathrm{Cu}-\mathrm{Ti}$ alloys. Materials Science and Engineering: A 1999;259(1):3442 .

4. Nagarjuna S, Balasubramanian K, Sarma DS. Effect of Cold Work on Precipitation Hardening of Cu-4.5 mass \% Ti Alloy. Metallurgical Transactions. 1995;36(8):1058-1066.

5. Nagarjuna S, Balasubramanian K, Sarma DS. Effect of prior cold work on mechanical properties and structure of an agehardened Cu-1.5wt \% Ti alloy. Journal of Materials Science. 1997;32(13):3375-3385.
6. Saji S, Hornbogen E. Combined recrystallization and precipitation reactions in $\mathrm{Cu}-4 \% \mathrm{Ti}$ alloys. Zeitschrift fur Metallkunde. 1978;69:741-746

7. Hernandez-Santiago F, Cayetano-Castro N, Lopez-Hirata VM, Dorantes-Rosales HJ, Cruz-Rivera JJ. Precipitation Kinetics in a Cu-4 mass \% Ti Alloy. Materials Transactions. 2004;45(7):2312-2315.

8. Hameda AA, Blaz L. Microstructure of hot deformed Cu-3.45wt \% Ti alloy. Materials Science and Engineering: A. 1998; 254: 83-89.

9. Ikeda J, Semboshi S, Iwase A, Gao W, Sugawara A. Precipitation Behavior and Properties of Cu-Ti Alloys with Added Nitrogen. Materials Transactions. 2015;56(3):297-302.

10. Semboshi S, Nishida T, Numakura H. Microstructure and mechanical properties of $\mathrm{Cu}-3$ at. \% Ti alloy aged in a hydrogen atmosphere. Materials Science and Engineering: A. 2009;517(12):105-113.

11. Wang F, Li Y, Wakoh K, Koizumi Y, Chiba A. Cu-Ti-C alloy with high strength and high electrical conductivity prepared by two-step ball-milling processes. Materials and Design. 2014;61:70-74.

12. Markandeya R, Nagarjuna S, Sarma DS. Precipitation hardening of $\mathrm{Cu}-\mathrm{Ti}-\mathrm{Cr}$ alloys. Materials Science and Engineering: A. 2004;371(1-2):291-305.

13. Donoso E. Influence of cobalt and chromium additions on the precipitation processes in a $\mathrm{Cu}-4 \mathrm{Ti}$ alloys. Revista de Metalurgia. 2010;46(6):542-547.

14. Nagarjuna S, Srinivas M. Grain refinement during high temperature tensile testing of prior cold worked and peak aged $\mathrm{Cu}-\mathrm{Ti}$ alloys: Evidence of superplasticity. Materials Science and Engineering: A. 2008;498(1-2):468-474.

15. Thermo-Calc Software. Cudemo-Mocudemo. In: Thermo-Calc Software Package Version 2017b. Solna: Thermo-Calc Software; 2017.

16. Kostorz G, ed. Phase Transformations in Materials. Weinheim: Wiley-VCH; 2001.

17. Saucedo-Muñoz ML, Ortiz-Mariscal A, Lopez-Hirata VM, Villegas-Cardenas JD, Soriano-Vargas O, Avila-Davila EO. Precipitation analysis of as-cast HK40 steel after isothermal aging. International Journal of Minerals, Metallurgy and Materials. 2017;24(10):1125-1133.

18. Costa e Silva A, Nakamura L, Rizzo F. Application of computational modelling to the kinetics of precipitation of aluminum nitride in steels. Journal of Mining and Metallurgy, Section B: Metallurgy. 2012;48(3):471-476.

19. Hernandez-Santiago F, Lopez-Hirata VM, Saucedo-Muñoz ML, Dorantes-Rosales HJ. Gibbs-Thomson relationship for the precipitation in Cu-Ti Alloys. Materials Characterization. 2007;58(3):303-306.

20. Porter DA, Easterling KE. Phase Transformations in Metals and Alloys. New York: Chapman and Hall; 1992.

21. Janssens KGF, Raabe D, Kozeschnik E, Miodownik MA, Nestler B. Computational Material Engineering. London: Academic Press; 2007. 
22. Miyazaki T. A New Evaluation Method of Phase Decomposition by Utilizing the Macroscopic Composition Gradient in Alloys. In: Proceedings of the International Conference on Solid-Solid Phase Transformations ' 99; 1999 May 24-28; Kyoto, Japan. p. 15-22. 